\title{
How Can EFL Students Be Corrected Without Hindering Oral Participation?
}

Jimmy Ramírez Acosta'

Universidad Nacional, Costa Rica

\section{RESUMEN}

Se describen las técnicas que suelen emplearse para corregir la producción oral de estudiantes de segundas lenguas. Según la forma en que los estudiantes son corregidos, así su deseo de participar. Parte de la información proporcionada se fundamenta en una investigación llevada a cabo con un grupo de estudiantes de inglés en cuanto a sus ideas sobre modelos de corrección y sus propuestas.

\section{Abstract}

The error correction techniques commonly applied by teachers to improve students' oral output are described here. The way students' output is treated plays an important role in their desire to participate. Part of the information provided is based on research carried out with a group of students of English concerning their ideas about error correction and the techniques that they proposed.

Palabrasclave: adquisición y aprendizaje de idiomas, técnicas de corrección de errores

Keywords: language acquisition and learning, error correction techniques

I Correo electrónico: jimmyramirezacosta@gmail.com. 
Linguists have tried to understand not only why we make mistakes but also how to correct them, when to do so, and who should correct those mistakes in order to help students overcome these erroneous forms. Sometimes, however, teachers are not familiar with the most appropriate way in which they should correct students in order not to affect their motivation to participate. Traditionally in Costa Rica, those who have been trained to become teachers have been taught that the mistakes students make must be treated immediately, but they have not always been taught that the way that feedback is given might influence the students' learning and participation processes.

Error correction has always been a topic of interest due to its pedagogical consequences and it is because of this that many studies have been carried out in order to determine the impact correction techniques have on the students' behaviour toward participation. For example, authors such as Burt and Kiparsky, Chastain, and Grittner came to the conclusion that it is extremely easy to destroy the students' confidence when they are corrected inappropriately. ${ }^{2}$ Hendrickson ${ }^{3}$ found that correcting errors does improve the students' proficiency and that errors must be corrected in a supportive rather than critical way.

Many of us who have gone through the process of learning a foreign language will agree that one of the most inhibiting factors in any formal learning situation is the fear of making mistakes and being thought ridiculous by native speakers, classmates, or teachers. What would happen if a teacher asked a question and a very shy student, making an effort to overcome his nervousness and fear of failure, tried to answer the questions and he was corrected for every single part of the utterance he has produced? Will he ever want to participate again?

\footnotetext{
2 M. K. Burt \& C. Kiparsky, "Global and Local Mistakes," New Frontiers in Second Language Learning, eds. J. H. Shumann \& N. Stenson (Rowley, MA: Newbury House, 1974), 71-80; K. Chastain, The Development of Modern Language Skills: Theon to Practice (Philadelphia. PA: Center for Curriculum Development, 1971); Frank M. Grittner. Teaching Foreign Languages (New York: Harper, 1977).

3 James M. Hendrickson, "Error Correction in Foreign Language Teaching," The Modern Language Joumal VIII, 62 (1978): 387-398.
} 
Giving feedback is perhaps one of the most influential aspects in learning a language because students are given the necessary tools to correct their output and thereby improve their proficiency. However, some teachers may use a correction technique that destroys their students' self-confidence. The problem stated here is common to many English language teachers. We have perceived that the students' affective filter will be influenced if we overcorrect them and end up causing them to stop participating. The purpose of this article is to give some theoretical information on error correction and explain the impact some error correction techniques might have on students' oral participation based on an investigation that was carried out one year ago with a group of university students.

We will begin by defining some of the terms which will be used here:

Errors: Martin Parrot points out that errors "are considered to be evidence of the learner's developing competence in the foreign language... Errors are generally systematic."4

Ellis proposed another concept of error by saying that they are the result of lack of competence, and they are internalized into the language system. ${ }^{5}$ We can say that errors are those erroneous forms that are systematic and that are evidence of the learners' competence. Errors might take place because the learner does not know the correct form, or because he or she has not yet acquired it completely. For example, if we have a student who says "She don't cook well," we can say either that the student has not yet studied the simple present tense or that he still hasn't acquired that form This example may be considered an error if it is systematic (meaning that is repeated in many different ways), and if it confirms the learner's lack of knowledge.

Mistakes: Mistakes are the result of processing limitations rather than lack of competence. Mistakes could emerge because the student or the speaker is more concerned about communication rather than

Martin Parrott, Tasksfor Language Teachers (Cambridge, Cambridge University Press, 1993).

Rod Ellis, Understanding Second Language Leaming (Oxford: Oxford University Press, 1994). 
an accurate use of the language. Mistakes might take place because of many aspects such as stress or fatigue.

According to Edge, "Mistakes can be caused by the influence of the first language, by misunderstanding a rule, by a decision to communicate as best as one can, by lack of concentration, and by a combination of these and other factors." 6 This might happen when students try to improve their fluency by trying to speak faster but in their attempt to do so, they stop concentrating on other factors of their output such pronunciation, grammar, vocabulary.

Edge points out that "Mistakes are generally non-systematic and do not necessarily reflect the learner's underlying competence... Learners will normally be able to identify and correct their mistakes if they are prompted to do so...."7 Let's picture the case of a student who is giving a speech and suddenly he says, "Lolita can't to go to the party," and he immediately repairs this utterance by saying, "Sorry! Lolita can't go to the party." In this example we can see that the student is making a mistake but immediately repairs the utterance by giving the correct form.

Fossilized forms: Fossilization is a process in which learners internalize an erroneous linguistic pattern in their minds; these erroneous linguistic patterns might not be persistent, but as soon as the learners focus on communication and not on form they will backslide toward this erroneous interlanguage form.

Selinker also noted that many L2 learners fail to reach target language competence; that is, they do not reach the end of the interlanguage continuum. They stop learning when their interlanguage contains at least some rules different from those of the target language system. ${ }^{8}$

Once a student has a fossilized form, it is difficult to remedy with further instruction. Ellis proposed that fossilized form can be considered either errors or correct target language forms. For example, we can say

\footnotetext{
Julian Edge. Mistakes and Correction (London: Longman, 1989) 7.

Ellis. 7.

Ellis, 45 .
} 
that a correct fossilized target language form would be one that is the same form in the interlanguage as it is in the target language. A negative fossilized form would occur when the learner has reached a stage in which a structure does not have the same form in the target language.

According to Selinker and Lamendella (cited by Ellis), fossilization might have internal and external causes. A learner may believe that he has already learned enough to communicate his ideas with some degree of appropriateness, and this learner might not feel the necessity to develop his interlanguage any further. Another possible cause of fossilization can be changes in the neural structure of the brain which means that as a result of age the brain may restrict the operation of the hypothesis testing mechanisms.

Interlanguage: Interlanguage is a concept used to refer to the process of learning a second language, which is characterized by different language stages; these stages will help us identify where a learner is in his/her process of L2 acquisition. It has to do with the language proficiency levels that learners go through, and it is dynamic, variable and permeable. ${ }^{9}$

Let us picture two students presenting a role-play in front of the class. One of them asks, "Can she go," the other one replies, "No, she don't can to go." In this example, we can see that the structure that one of the students is using in this case does not belong to his L1 or to his L2. That is what interlanguage entails; it is the result of the knowledge and hypotheses you create in your mind in order to learn the language. "Hypothesis-testing" is the process in which the students test out the hypotheses about structures, vocabulary, pronunciation that they have in their interlanguage. From the previous example, it is clear the student was testing his knowledge, and by making mistakes, he was learning. We have to keep in mind that making mistakes is evidence of learner-internal processing.

Ellis, 42. 


\section{What causes errors?}

If we ask a group of teachers what causes errors, they will probably come up with similar answers. Some of them will support the idea that some of our students are careless, and some other teachers with some linguistic knowledge may support the idea of first language interference or translation. I will briefly discuss some of the most relevant aspects why students make mistakes.

\section{Carelessness}

When we speak, we might sometimes make mistakes because we are more concerned about what we are saying than how we are saying it. It is clear than even in our native language we can make mistakes that could have been easily prevented if we had paid attention to what we were saying. Let's picture the case of a Spanish speaker in a noisy class; he is tired of listening to so much noise and he says, "Cállensen." In the previous example it is clear that the speaker might not have made the mistake if he or she hadn't paid too much attention to the message rather than the form. If carelessness is a cause of errors in our native language, so it is when we are learning another language.

\section{First Language Interference}

Skinner (Cited by Norrish) provided the concept of "mothertongue interference" meaning that learning a language was habit formation, and that when we try to learn new habits the old ones will interfere with the new ones. ${ }^{10}$ This means that when we learned our mother tongue we shaped our sentences to those of our parents and people we listened to; we were somehow rewarded if our use of the language was to some extent appropriate and we started to repeat the sentences and this led us to form a linguistic habit. These linguistic habits are the ones that will interfere in our process of learning a foreign language.

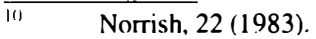


Susan Gass and Larry Selinker agree that the information from our native language interferes with our learning process: "The role of the native language took on great significance, because it was the major cause for lack of success. The habits established in childhood interfered with the establishment of a different set of habits." 11

\section{Translation}

There is a fine line between translation and interference. Translation is a conscious and voluntary process whereas interference is an unconscious and involuntary process. When learners undergo this process, they might translate idiomatic expressions word by word. Sometimes students have to express their ideas and they might use a dictionary to help them cope with that task; when this happens other errors might come up. Another possible reason is that when learners do not know how to express something in the target language they will fall back on the language system with which they are familiar, namely that of their mother tongue.

\section{Overgeneralization}

Overgeneralization takes place when a student extends a rule to a context of the target language; and this usage is incorrect. For instance, the past tense marker in English is “-ed", students understand that for a regular verb to be turned into a past one they just need to add "-ed." They might come up with sentences such as: "I drived the car yesterday." In this case the students are assuming that just by adding -"ed" to the verb "teach," they are properly expressing their ideas. As Ellis stated, overgeneralization might take place because of ignorance of rule restrictions which means that students might not understand when to apply and when not to apply a given rule. ${ }^{12}$

\footnotetext{
II Susan Gass \& Larry Selinker, Second Language Acquisition: An Introductory Course (New Jersey: Lawrence Erlbaum Associates Publishers 1994) 59. 


\section{Which Errors to Correct}

Many teachers might not yet understand what errors to correct, and some others might argue that correction is absolutely necessary whereas some other might disagree completely. The point that should be clear by now is the fact that teachers should be selective with the mistakes or errors they correct.

Teachers should pay attention not only to how the students are expressing their ideas, but also to the message itself that is being expressed. According to Allwright, these are the first two aspects that teachers should consider. Only then should the teacher worry about the frequency and the pedagogical focus. For example, if we have been working with the simple present tense, and the students show some frequency of errors in the use of the third person singular, teachers should correct those mistakes promptly.

Johnson (cited in Walz) also agrees with Allwright that teachers should first of all pay attention to errors that interfere with the comprehension of a message and that cause a negative reaction on the part of the listener. ${ }^{13}$ Another system for evaluating errors based on the students' proficiency is proposed by Hendrickson (cited in Walz). He suggests that in the elementary level we should only correct errors that impede communication, in an intermediate level we should only correct errors that occur frequently, and in advanced levels we must correct errors that have a stigmatizing effect upon the student. ${ }^{14}$ Another important aspect mentioned by Cohen (also cited in Walz) is that teachers should pay attention to the particular characteristics of the students, including the individual differences such as native language, personality factors, past history, and the level of motivation, anxiety, or fatigue. ${ }^{15}$

\begin{tabular}{ll}
\hline 13 & Walz 7. \\
is & Walz. 8. \\
is & Walz, 9.
\end{tabular}


We can devise this system for deciding which errors to correct derived from comprehensibility, frequency; pedagogical focus, and individual student concerns.

Comprehensibility. Teachers should correct errors that cause a misunderstanding or lack of comprehension because the main purpose of the language is to communicate ideas. Experienced teachers and those who share the same native language as the students can take advantage of it by watching for mistakes of this kind and correcting them as soon as they appear. Monolingual speakers of the target language will not be capable of correcting them because they will have no idea of what the speaker is trying to say. If you are teaching passive voice and once you finish, one of your students says, "Teacher I am behind the tree." A Costa Rican would definitely understand what the student wants to say, but a native speaker of English will be completely clueless as to what the student wants to convey with that utterance.

Frequency. This can refer to errors made by an entire class or by individual students. A frequent error is usually made on a common grammar point. Errors which are frequent should be corrected as soon as possible so that they will not fossilize.

Pedagogical Focus. "If a class spends time studying a particular grammar feature and then an error occurs and goes uncorrected, all the students who hear it will begin to question their own understanding of the structure." ${ }^{\prime 6}$ For example, if the present perfect has been taught in a class and a students says, "He has go to Limón," the teacher should correct the mistake immediately for the well-being of the students of the class. The students in that class are intended to use the present perfect properly, and if they are not given proper feedback, they will not be able to amend their erroneous utterances.

Individual student concerns. Teachers should always know their students and learn who are the most sensitive to correction. For example, adults will find it useful if their grammar is corrected, but

Walz, 11 
imagine what would happen if you correct a four-year-old child using grammatical terminology. Some students might appreciate being corrected quite often whereas others are more easily inhibited.

\section{Who Should Correct?}

Jiménez wrote, "The teacher is not the only person in the class capable of correcting the errors. The errors can also be self-corrected, or could be just as well treated by another student, by a group of students, or the whole class. There is also the possibility of letting the students do some research to find out the correct form or even ask someone outside the classroom."17

Teachers are no longer the only source of knowledge as they tended to be considered in the Grammar Translation method. We have to be clear that students can correct themselves and correct others. A hierarchy of people who should make corrects will go as follows: first, the student who made the mistake (self-correction); second, a classmate who is capable of correcting the mistakes (peer-correction), and finally the teacher (teacher correction).

\section{Self-correction}

Self-correction is understood as the process in which erroneous statements are corrected by the person who made them. Self-correction reduces teacher talk and might reduce the fear factor that excessive correction can cause students. Self-correction is also beneficial due to the fact that when students correct their own mistakes, they get a feeling of being self-sufficient in the use of the target language. A positive aspect of self-correction is that we are telling our student that we trust them, that they have the capacity to correct their own mistakes and that self-correction is easier to remember because someone has put something right in his or her own head.

1) Ivannia Jiménez, "Treating Students' Errors in Oral Production," Letras 36, Heredia (UNA) 2004, 185. 


\section{Peer-correction}

Peer correction is a way to involve students actively in the learning process. It is also less threatening; however, there are some students who would prefer being corrected by the instructor of the course rather than being corrected by one of their classmates. In his book Error Correction Techniques for the EFL Classroom, Walz established four advantages of using peer-correction:

1. It motivates students who previously thought a foreign language was impossible to learn, because they see their classmates using it correctly.

2. Peer-correction involves a great number of students in the running of the class.

3. The correction tends to be at a level that others in the class can understand.

4. Peer-correction increases the amount of time students talk in class and reduce the amount of time the teacher must talk. ${ }^{18}$

\section{Teacher-Correction}

If self-correction and peer-correction fail at first, the teacher should help students correct their own mistakes. This does not mean that the teacher is going to give the correct form to the students right away. What the teacher can do is to help the students focus their attention on the particular part of the language that is faulty. You may be wondering why an instructor should not give feedback immediately if self-correction and peer-correction have failed. When students make hypotheses about the language they are learning, they usually test them, and thereby they must have the ability to test out their hypotheses and determine whether they are valid. If the instructor gives the students the correct form, the information that is given to the students is not as meaningful to them as the information the students could have obtained if they had proved their hypotheses themselves.

Walz, 17. 


\section{Correction Techniques}

Teachers should always correct gently and respectfully when students are involved in an oral activity in particular, where correction will take place in front of all the students' classmates. Vigil and Oller (cited by Walz) stated that "There are many ways in which teachers can correct students; however, the way they treat errors should never be predominantly negative feedback, because this would discourage students' participation." 19

There is a consensus among many scholars that teachers should place more emphasis on correction during drills than during communication activities. The reason is because drills stress linguistic patterns and accuracy, whereas communication activities involve time for the students to experiment and express themselves however they can.

These are some of the most common correction techniques applied by teachers in EFL classes.

\section{Negative Feedback}

Saying "No" is clearly negative feedback, but it does not tell the student what he did wrong. This technique is not appropriate because it might have a negative effect on the students' affective filter. If teachers implement this technique the students might not want to participate anymore because they might feel afraid of making a mistake and not knowing what they did wrong. Teachers usually use this technique because they might assume that the student has simply made a slip under pressure, and that this does not therefore represent a lack of knowledge of the subject matter.

Negative feedback can have different variations such a facial expression or a shake of head that might give the student a clue that a mistake has been made. Some other teachers might try to soften the negative force of "NO" by, for example, making a mmmmm noise or

i) Walz, 16 .

116 
they might say, "Well, that's not entirely correct, but thanks anyway." Whatever the form that is used, it will always leave the students wondering if they have really made a mistake.

\section{Utterance Repair}

This is a correction in the strictest sense of the word. The teacher corrects the students' erroneous utterance. Teachers might do this because they are interested in maintaining the flow of the conversation, but at the same time, they want to remind the students that they have to focus not only on meaning but also on form.

The problem with this type of correction technique is that it has been widely criticized, and its effectiveness has not been proven to help students to overcome their linguistic limitations.

\section{Pinpointing}

Another widely used technique is pinpointing. In this technique the teacher is expected to repeat the sentence for the student to identify the error. It has been shown to be successful if the student is really paying attention to what the instructor is saying. Sometimes what the students need is to be told what part of what they have said is not correct, and this is a good way of doing it.

Knop (Cited in Walz) suggests that the best way of applying this correction technique is by emphasizing the last word before the error. Teachers can do this by lengthening the vowel, trailing intonation, and this will allow the students to catch the idea that the fragment needs to be corrected again. ${ }^{20}$ This technique is useful because it not only gives the learner a clue to where the mistake is, but also encourages self-correct. Let's look at the following example.

S: She climbed. /V \& /_d/

T: $\quad$ She ......

S: $\quad$ She climbed.

$\overline{20} \quad$ Walz, 18. 


\section{Request for Clarification}

Requests for clarification are frequent in real conversation; expressions such as I'm sorry, I didn't understand, Sorry?, He what?, Excuse me? are part of this type of correction. As a correction technique it is good because it tells the students that what they said was unclear or incorrect.

This is a very friendly way of telling students that a mistake has been made. "Research suggests that when learners re-cast their message after receiving a clarification request, it usually tends to improve, despite their not having been told explicitly that a mistake has been made." 21

A variation of this technique could be questioning; that term was proposed by Burt and Kiparsky (cited in Waltz). ${ }^{22}$ In this case if a student uses a word that the teacher or listener does not understand, the teacher should ask a question about it. The student is expected to reveal the meaning of the word without recourse to the native language and without making an obvious correction. Waltz provides an example of how this technique works:
S: I am studying to be [incomprehensible word]
T: Why do you want to do that?
S: I like to help people.
T: How will you help them?
S: $\quad$ They can see better.
$\mathrm{T}$ : Yes, an optometrist does that.

\section{Literal Interpretation}

The students' erroneous forms are interpreted in order to show the student the unintended effect of the error, on the principle that once the learner appreciates the difference between the erroneous and 21 $\quad$ Scott Thombury, How to Teach Grammar? (Harlow, England: Pearson Education, 1999) 20.
$\because \quad$ Walz, 20. 
the correct form, he or she will be less likely to make the same mistake. Let's look at the following example:

S: He has a long hair.

T: Just one? Like this? [Draws a bald man with one long hair] Ha ha...

\section{Reactive Teaching}

When teachers use this technique, they usually take advantage of the students' mistakes to make an impromptu teaching point. This means that instruction is going to be based on the mistakes the students make. As Thornbury pointed out, "If teachers were to do this at every mistake, the classes would not only become very teacher-centered, but the students might become reluctant to open their mouths." 23

There are several variations of this correction technique; one of them is the use of grammatical terms to locate an error. The teacher will tell the student where the error is by mentioning the function it has in the sentence. The advantage of this technique according to Waltz is that this practice prevents destroying the student's chain of thought in the middle of a long sentence. One important aspect to mention about this technique is that it focuses not only on linguistic correctness but also on communication.

\section{Reformulation}

Reformulation is when teachers correct their students as parents do with children. Parents usually offer a correct version of what the child has said. The same principle takes place here. This correction technique is important because it enables the student to continue talking. There is, however, one important problem: sometimes students do not see the difference between their statement and the one provided by the teacher. One way to solve this is to get the students accustomed to this type of error correction technique.

23 Thombury, 92. 
This technique has many advantages; one is that students do not feel humiliated because the way that feedback is given is natural. Students do not lose track of what they are saying because this technique does not expect students to repeat the correct form of the sentence. The idea behind this technique is to catch the students' attention and direct it to the error. Consider the case of a student who comes late to class and he takes a quiz in a hurry.

S: $\quad$ (Handing in quiz) I am sorry professor my font is terrible.

T: Oh no! Don't worry. Your writing is just fine.

S: Thank you!

In the previous example, the student got the correct form, but is not expected to repeat it. The student must realize that the structure or the word used was not appropriate. By using this technique students are not humiliated and they are allowed to continue talking. However, at times when the student has made no error at all and the instructor inadvertently uses a synonym for one of the words, students can conclude that they have made a mistake.

\section{Delayed Correction}

In this case, the teachers write down the errors for future reference and discussion. The idea is to postpone the feedback in order not to disrupt the flow of talk, but deal with errors later. This type of technique might be recommended when students are involved in communicative activities. Teachers can give students feedback once they have finished the activity. The teacher can go to the board and write the mistakes that the students have made, or the teacher can even ask them to try to correct their mistakes on the board in order to make it more meaningful for them. 


\section{Personality Factors}

One of the most important aspects an instructor can take into consideration during class is the personality of each student. Brown has argued that "The affective domain is the emotional side of human behaviour, and it may be juxtaposed to the cognitive side. The development of affective states or feelings involves a variety of personality factors, feelings about ourselves and about others with whom we come into contact." 24 Understanding how human beings feel, respond, believe, and value is an extremely important aspect of how learners acquire a second language.

When learners have a positive view toward the learning process, they may be more successful in acquiring the second language than people who are not motivated. This means that if your affective filter is low, you are more open to learming and acquiring the language successfully. You are likely to look for situations in which you can get more input and practice what you have learned confidently, with speakers of the target language. In addition, people with a low affective filter are expected to be more receptive to input.

Some of the most important personality factors, such as selfesteem, inhibition, and willingness to take risks, are discussed below.

\section{Self-esteem}

For most instructors, self-esteem is probably the most persistent aspect of human behaviour. Most professionals believe that no successful cognitive or affective activity can be carried out without some degree of self-esteem. This means that students should believe in their knowledge, and their own capacities for the activity that is being carried out. Coopersmith (cited in Brown) defines self-esteem as "The evaluation which the individual makes and customarily maintains with regard to himself: it expresses an attitude of approval

24 Douglas Brown, Principles of Language Learning and Teaching (New Jersey: Prentice Hull Regents, 1994) 135. 
of disapproval, and indicates the extent to which an individual believes himself to be capable, significant, successful, and worthy." 25

Adelaide Heyde (cited in Brown) studied the effects of selfesteem on the performance of an oral production task by American college students leaming French, and found that self-esteem correlated positively with performance on oral production measures. The results revealed that self-esteem appears to be an important variable in second language acquisition. ${ }^{26}$

According to Brown, teachers can have a positive and influential effect on both the linguistic performance and the emotional well-being of the student. It is said that perhaps those "good" teachers have succeeded because they gave optimal attention to the linguistic goal but they did not forget the personhood of the student. ${ }^{27}$

If the correction techniques that teachers employ to give feedback to the students are aggressive rather than supportive, we are likely to affect the students' self-esteem and consequently their acquisition of the target language. Sometimes teachers focus so much on linguistic elements that they forget that their students are human beings. Consider, for example, a student whose self-esteem is not good, but who tries to participate in class and use the target language as properly as possible. Every time he starts speaking the instructor stops him, as soon as an erroneous structure comes up. He is being humiliated in front of his class, and thereby his self-esteem is affected. The teacher could have prevented this by using a supportive type of correction. There are times in our classes when students want to say something meaningful and they want people to listen to what they are saying and not how they are saying it. 


\section{Inhibition}

The concept of inhibition is closely related to the concept of selfesteem; all human beings in their understanding of themselves develop ways of defending themselves to protect their ego. According to Brown people with a high self-esteem and a strong ego are more able to withstand threats to their existence. ${ }^{28}$ On the other hand, those with weaker self-esteem maintain walls of inhibition to protect what may be perceived as a fragile ego.

Teachers sometimes implement correction techniques that give the students the idea that if they want to say something, they have to say it correctly; otherwise, it would be better to say nothing. We have to change that idea completely in our students and let them know that if theynever take the risk of saying something, until they are completely sure that what they are saying is error-free, they will nevercommunicate productively at all.

\section{Risk-Taking}

We all know that learning a language entails making mistakes. We test out our hypotheses about the target language by trial and error. It is said that children learning their first language and adults learning a target language can only make progress and succeed by making mistakes. Risk-taking is an important factor for successfully learning a second language, because it allows learners to "gamble" a bit; this means that learners test out their hypothesis and they take the risk of being wrong.

Instructors should encourage students to take risks during the foreign language class, and this is only done by telling students that making mistakes is a natural process of testing linguistic hypotheses. Educators should keep in mind what Beebe (cited in Brown) said: "They fear looking ridiculous; they fear the frustration of coming from a listener's blank look, showing that they have failed to communicate;

$\overline{28} \quad$ Brown, 139. 
they feel the danger of not being able to take care of themselves; they fear the danger of not being able to communicate and thereby get close to other human beings." 29

Teachers above all should value students as people who take the risk of participating and being wrong. Educators should not overcorrect students because this will reduce the students' desire to participate at all.

\section{The Survey}

This survey focused on error correction and the impact a given error correction technique has on the students' willingness to participate. The results of this survey will be discussed below, and can help teachers improve their error correction techniques in order to enhance oral participation.

Sixty university students were given a questionnaire in which there were asked about the error correction techniques commonly applied by their teachers and the impact those techniques had on their participation. These students were taking the last English course in a private university and were selected due to the fact that they had a broader view on how they had been corrected throughout the program. The fact that these students were taking the last English course gave valid information because, by this time, the students really knew what error correction techniques were useful, which ones they wanted their teachers to implement, and which ones were useful to promote their participation.

\section{When do students want to be corrected?}

Sixty percent of the students who were interviewed agreed that they wanted to be corrected at the end of the communicative activity in front of everyone. Students mentioned that this will allow them to continue talking. They find that being corrected immediately is not so

ii) Brown, 139. 
useful because they sometimes repeat the correct form that is provided by their teacher or peers, but they are not really focusing on the new input that is being given.

\section{Who should correct students' mistakes?}

Many of the students think that the teacher should be the first person involved in giving feedback, and this is supported by $52.7 \%$ of all the students who were interviewed. Self-correction was supported by only $33.3 \%$ of the students while peer-correction was given the last place with only $14 \%$. This information goes against the correction hierarchy proposed by Julian Edge who suggests that teacher-correction should be implemented only when self-correction and peer-correction have failed. Students strongly disagree with peer-correction because believe that teachers sometimes ask the same students to correct their peers' output and the others get the feeling that they are being humiliated and criticized in front of everyone.

\section{What correction techniques should teachers not apply?}

1. Saying "no" is perhaps the strictest way for correcting a student and based on the information provided by the students; they do not want teachers to correct them using this technique. One of the reasons for such a decision is the fact that students are given no clue as to what they did wrong.

2. Almost $80 \%$ of the students disagree with teachers who use request for clarification. This correction technique implies asking the students if they are sure of what they have said. Students consider that this correction technique is humiliating, and it doesn't give the student a hint on what they did wrong.

3. Literal interpretation implies interpreting the students' output literally; this means that if a student says "I am very lizard" instead of "I am very lazy", the teacher is supposed to translate the student's utterance literally into the student's native language. 
So the teacher will probably say, "Ah, usted es muy lagartija." According to the information provided by the students they do not want to be corrected using this type of correction technique, $76 \%$ of the students disagree with this type of correction because they find it humiliating.

\section{What correction techniques should teachers apply?}

1. Reformulation implies giving feedback to the students in a way in which the students' ideas are not interrupted. For example; if a student says, "She don't cook," the teacher might reply "Oh! Why doesn't she cook?" During the interview 95.2\% of the students stated that they would like their teacher to correct them using this technique. They find that this technique doesn't cut their track of thought, does not cause stress, and it is not humiliating.

2. Over $60 \%$ of the students said that they want their teacher to give a brief grammatical explanation about the mistake they have made. They support the idea that it is sometimes necessary to get additional information about their mistakes. Students consider that the teacher's explanation will help them correct their output.

3. Pinpointing implies repeating the students' erroneous sentence up to the point where the mistake took place. Some $67 \%$ of the students seem to agree with the idea that pinpointing is a good correction technique, and say that this correction technique helps them learn to self-correct their output.

The information gathered from this survey is summarized in the diagram below. 


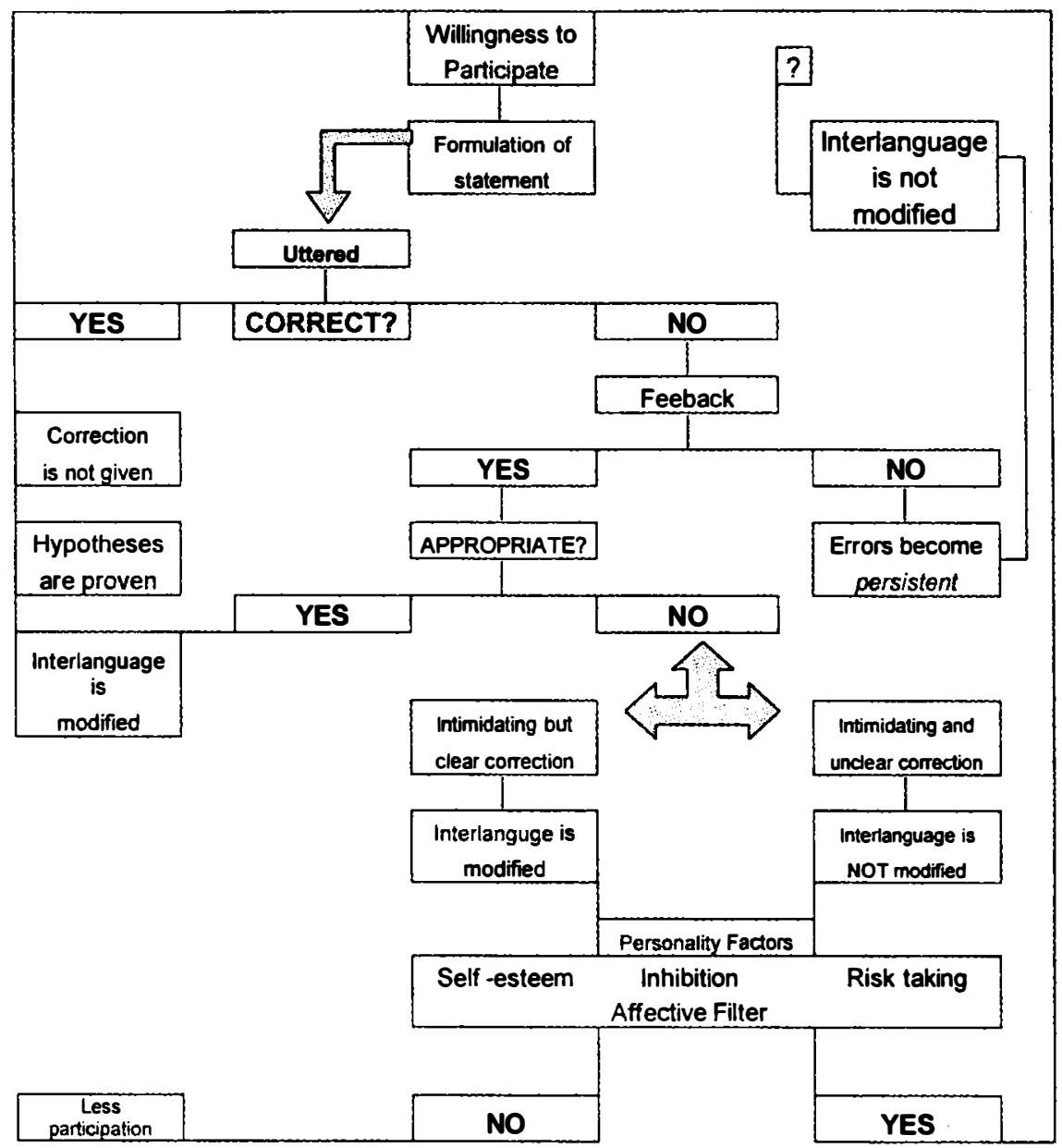

In the first stage of the whole process, we have the students' willingness to participate and it is in this stage where students usually fight against many factors such as anxiety, fear of failure, stress, etc. After this stage, we have formulation of statement in this stage students think about what they want to say and how they want to say it. The student's interlanguage plays an important role in this stage because 
it is here where students decide on the hypotheses that they are going to test. When the students have formulated their statements, they are going to utter them. If the uttered form is correct, the student is not likely to be corrected. The students, then, are going to learn that what they have said is correct, their hypotheses on the use of the language are going to be proven, their interlanguage is going to be modified, and chances are that the students are going to feel eager to participate again.

On the other hand, if the statement uttered is not correct, the teachers or the facilitators provide feedback on the students' erroneous forms. When feedback is provided, we have to analyze whether it is appropriate, supportive, and clear. This survey shows that students feel that reformulation, reactive teaching and pinpointing are the most appropriate and supportive correction techniques that can be implemented. When students are corrected appropriately and supportively, they are likely to modify their interlanguage and are more likely to participate again.

When teachers do not provide appropriate feedback, two processes may take place. The teacher provides feedback using an intimidating but clear correction technique. A good example of a clear but intimidating correction technique is literal interpretation. This type of correction technique helps students learn that they have done something wrong. In this case the students' interlanguage is modified because they can somehow amend their output after they have been corrected. This takes us to motivational factors which will influence the students' willingness to participate again. If their self-esteem is low, their affective filter is high, and if they are corrected inappropriately, they will start participating less. This occurs because the instructor's technique for giving feedback does not help the students take risks to participate and make mistakes. These students might not feel comfortable about themselves, and the teacher is not making them feel any better. On the other hand, if the way the student is corrected is inappropriate but the student has high self-esteem and a low affective 
filter, this student is likely to participate again due to the fact that their perception of themselves is stronger that the negative effects that an error correction technique might have on them.

If the feedback provided is intimidating and unclear (saying "no" or making clarification requests), the students are not likely to modify their interlanguage and their participation will depend on whether they are able to deal effectively with the inappropriate correction technique used. Students are likely to deal effectively with this type of correction if their self-esteem is high, their affective filter is low, and if they are willing to take risks.

Finally, when feedback is not given, errors tend to become persistent, and later on fossilized, the students' interlanguage is not modified and their willingness to participate will not be so certain. Students continue participating and making mistakes up to the point when they get some type of feedback, or remain in silence.

The data from this survey are summarized below:

1. Almost eight five percent of the students said that they decided to remain in silence because they did not like the way in which their teacher corrected them. This means that the correction techniques the teachers were using affected the students' willingness to participate.

2. When thinking about all of the courses they have taken, $62 \%$ of the students said that their desire for participation has diminished because of the way their teachers have corrected them. This is important because we can see that a high percentage of students think that the way they were corrected did not match their expectations.

3. Almost $90 \%$ of the students consider that teacher should take into consideration the students' abilities when correcting. Students think that this is an important aspect due to the fact that teachers are not supposed to correct all the students in the same way. Even in the same class with a very heterogeneous group, 
teachers should elicit correction techniques that match the students' needs and abilities.

\section{Implications}

How teachers deal with errors has a significant impact on the students' performance and desire for participation. To improve oral participation in our classes, it is advisable to talk with our students about errors and find out how they want to be corrected, because not all of them want to be corrected the same way. Teachers should not over-correct students because that can shatter a student's confidence. However, instructors should correct errors considered to interfere with communication, stigmatize the learner, and appear frequently.

When correction is required, it is also important to take into account the level they have. For instance, beginners should only be corrected on errors hindering communication, intermediate students should be corrected when errors are frequent, and advanced students must be corrected on errors that stigmatize them.

Finally, the correction techniques that a teacher uses are based on the teachers' beliefs as well as the students' beliefs. It is advisable to try different techniques for dealing with the students' mistakes; by so doing, both students and teachers will be able to determine which techniques are particularly more useful in their learning context. 